\title{
Sobre la protección de la colaboración de los Animales No Humanos como titulares de derechos sociales
}

\author{
Ulises Nelson Medina Álvarez \\ Universidad de Buenos Aires \\ ORCID: https://orcid.org/0000-0002-4891-2741
}

Recepción: Marzo 2021

Aceptación: Mayo 2021

Cita recomendada. MEDINA ÁLVAREZ, U.N., Sobre la protección de la colaboración de los Animales No Humanos como titulares de derechos sociales, dA. Derecho Animal (Forum of Animal Law Studies) 12/2 (2021). - DOI https://doi.org/10.5565/rev/da.564

\section{Resumen}

Desde una aproximación socio-jurídica, se realizará un análisis de las principales formas de colabora-ción observadas en distintos animales no humanos, tanto en sus interrelaciones como especies así como con otros seres sintientes, incluyendo al ser humano en un plano de igualdad. El abordaje de estudio es de un carácter animalista, rescatando las principales tendencias que han surgido desde el derecho, la sociología y otras ciencias conexas respecto a la condición de los animales no humanos como titulares de derechos, así como los argumentos existentes para proteger sus derechos en una dimensión colectiva, sin perjuicio de analizar las normativas actuales locales e internacionales, con-tribuyendo desde lo actual a un debate muy abierto a propósito del sufrimiento animal.

Palabras clave: Derechos Animales; Derechos Humanos; Animales No Humanos; Sujetos de Dere-chos; Colaboración; Derechos Sociales; Especismo; Animalismo.

\section{Abstract - On the protection of the collaboration of nonhuman animals as holders of social rights}

An analysis of the main forms of collaboration observed among different nonhuman animals has been carried out through a socio-juridical approach. The analysis considers the interrelations of ani-mals both within a species and with other sentient beings, including with human beings on an equal footing. The approach of the study is animalist by nature, accounting for the main tendencies that have arisen through law, sociology and other related sciences regarding the condition of nonhuman animals as rights holders, as well as the existing arguments for protecting their rights in a collective dimension, analysing current local and international regulations so as to contribute to a very open debate on animal suffering.

Keywords: Animal Rights; Human Rights; Non-Human Animals; Subjects of Rights; Collaboration; Social Rights; Speciesism; Animalism. 


\section{Sumario}

1. Introducción

2. La colaboración de los Animales No Humanos y Humanos.

3. La colaboración entre Animales No Humanos de la misma especie.

4. La colaboración entre Animales No Humanos de distintas especies.

5. Sobre la necesidad de proteger jurídicamente la colaboración animal no humana.

6. Derechos fundamentales básicos de los sujetos de derecho animal relacionados con la colaboración. Argumentos y consideraciones en favor de su reconocimiento

6.1. Derechos Fundamentales Colectivos y Animales No Humanos.

6.2. Argumentos en favor del reconocimiento de derechos colectivos animales

7. Conclusiones.

8. Bibliografía.

\section{Introducción}

Desde tiempos antiguos que los animales no humanos han tenido un reconocimiento por parte de la filosofía y la biología, principalmente en cuanto a sus facultades sensitivas. Aristóteles, por ejemplo, consideraba que el ser humano, o Antrophos, era un Zoon Politikón, es decir, un Animal Político. Con ello ya estaba marcando una noción de igualdad entre el humano y otros animales, lo que no significaba una igualdad jurídica.

En el derecho, es Ulpiano quien considera por primera vez que existe un Ius Natural, que la naturaleza enseña a todos los animales, siendo estos sabios en este Ius. Lo anterior significaría que Ulpiano ya esbozaba una teoría antropológica del derecho, por lo que varias de nuestras construcciones jurídicas tendrían orígenes "salvajes", a través de un comportamiento enseñado por la naturaleza misma1. Compartiendo esta visión, inferimos que en el mundo antiguo se entendía que todos los seres vivos, inclusive el humano, eran animales. De hecho, la raíz etimológica de la palabra animal viene del latín "animalis", que hace referencia a seres animados o vivos.

Pues bien, existen tendencias jurídicas que sostienen que los animales no humanos son sujetos de derechos, lo que emana de su calidad de seres sintientes, como ocurre con el caso de la Orangutana Sandra, en Argentina, donde incluso se le llegó a considerar persona no humana por parte de una sentencia judicial ${ }^{2}$.

Esto nos demostraría la necesidad de superar los paradigmas surgidos en tiempos de Savigny y profundamente desarrollados por Hans Kelsen y el positivismo jurídico, cuando se impuso que el concepto de Persona es privativo sólo a los humanos, marcando así una injusta diferenciación, fomentada además por las ideas especistas.

En este sentido, Rabinovich-Berkman, indica que el concepto de persona para Kelsen es un término antropomórfico creado por la ciencia jurídica, por lo tanto es una construcción artificial, siendo un concepto jurídico más que biológico, por lo tanto prescindible ${ }^{3}$.

Pues bien, si se trata de una construcción artificial, no hay ningún impedimento en que la ciencia jurídica pueda referirse a los animales como "personas no humanas", en especial si culturalmente la humanidad así lo asume considerando sus similitudes con otras especies animales.

Actualmente la ciencia ha demostrado que existen animales que tienen la capacidad de asociarse y de comunicarse entre sí. Incluso existen casos en que sociedades humanas se asocian con otras especies no humanas para conseguir un objetivo común, lo que data de tiempos ancestrales. Por ello se requiere que el derecho proteja también estos fenómenos de colaboración interespecie.

\footnotetext{
${ }^{1}$ RABINOVICH-BERKMAN, R., Sobre las sociedades con otras especies, en Nuevos debates en filosofía y ciencia política, (2015) 8.

${ }^{2}$ LORA, L. De los sujetos no humanos como sujetos de derecho hacia los animales no humanos como titulares de derechos, en Instituto de Investigaciones Jurídicas y Sociales Ambrosio L. Gioja, Facultad de Derecho, Universidad de Buenos Aires, (2018) 5-8.

${ }^{3}$ RABINOVICH-BERKMAN, R., Nuevas reflexiones sobre el concepto de persona, en Inmanencia: Revista del Hospital Interzonal General de Agudos Eva Perón, Vol. 2, No 1 (2012) 5-7.
} 
Analizaremos a continuación ciertas manifestaciones de colaboración animal, y a continuación la actualidad socio-jurídica respecto a este punto. Advirtiendo, eso sí, que actualmente existen avances en el reconocimiento de derechos para los animales no humanos desde una perspectiva individual más que colectiva.

\section{La colaboración entre los Animales No Humanos y Humanos}

Cabe destacar que las disciplinas encargadas de estudiar el fenómeno de la colaboración animal fundamentalmente son la etología y sobre todo la antrozoología, que se dedica a estudiar las relaciones existentes entre seres humanos y animales no humanos. Comenzaremos este análisis profundizando en la relación con nuestros parientes más cercanos, que son los grandes primates.

En efecto, un grupo de destacados científicos, entre los que destacan la primatóloga Jane Goodall, en el año 1993, hicieron público el llamado "Proyecto Gran Simio" y la Declaración de los Grandes Simios Antropoideos. Se propusieron superar y profundizar la llamada Declaración Universal de los Derechos del Animal del año 1977. La pretensión es clara: Darle una protección legal y moral a los grandes primates y humanos como una comunidad de iguales ${ }^{4}$.

La figura de Jane Goodall es del todo relevante, toda vez que ella ha desarrollado prácticamente toda su carrera en el estudio del comportamiento del chimpancé africano por medio de su observación directa, conviviendo con ellos y estudiando sus conductas. Comprobó que estos animales tienen costumbres, sentimientos, formas de comunicación y normas de conducta que reflejan no sólo la existencia de una individualidad en un sentido rudimentario de personalidad, sino también que se trata de seres capaces de convivir racionalmente, a través de relaciones familiares y afectivas, relacionándose incluso con ella, a quién demostraban su cariño a través de besos, abrazos y caricias.

De esta manera, estas criaturas incluso colaboraban en el estudio que ella estaba realizando a través de una grata compañía. Incluso la científica dio nombres propios a muchos de estos primates respondiendo los chimpancés a ellos. Por lo tanto, las conductas de estos animales se asemejan con la de los seres humanos ${ }^{5}$.

Tampoco nos debiese extrañar esta situación, ya que desde el punto de vista genético, los humanos y los chimpancés compartimos un $99 \%$ de ADN. Esto fue comprobado por los científicos del Consorcio Internacional para el Genoma del Chimpance, trabajo publicado por la revista Nature en el año $2005^{6}$.

En otras latitudes, en Mozambique, la tribu africana de los Yao ha establecido un interesante fenómeno comunicativo entre seres humanos y otros animales, pudiendo de esta manera interactuar y comunicarse para conseguir un fin común. Existe un pájaro llamado Indicador Grande, que por medio de su particular sonido, es capaz de entenderse con los Yao para conseguir miel, en una relación que según el antropólogo Richard Wrangham, se remonta a los 1,9 millones de años, en los tiempos del Homo Erectus ${ }^{7}$, lo que nos demuestra la necesidad de proteger jurídicamente está particularidad cultural.

En el caso de los lobos, también existen indicios de una relación colaborativa que se remonta a más de 30.000 años. Así, Rabinovic-Berkman señala que existen registros en obras rupestres donde destacan cabezas de perro junto a los humanos en el África Central, lo que ha llevado a sostener a la antropóloga Pat Shipman que esta cooperación humano-animal fue vital en la construcción cultural humana, al punto que la alianza entre el Homo Sapiens y los lobos logró arrebatar el control de Europa a los Neardentales ${ }^{8}$.

Señala además que la alianza con los lobos responde a dos hipótesis, fundamentalmente consistentes en el acto de recoger crías de lobeznos pequeños por parte de los humanos para su crianza, o el hecho de acercarse a lobos adultos por parte de grupos humanos. Por lo tanto, existió una interacción consistente en una protección mutua.

Las consecuencias de estas interacciones generaron la evolución del lobo a lo que hoy es el perro, a propósito del fenómeno de la domesticación. A su vez, el humano logró desarrollar su membrana esclerótica a través de su crecimiento, algo propio de este tipo de homínidos, lo que responde directamente a una forma de comunicación no verbal entre ambos animales. Por eso el perro actual es capaz de reconocer señales realizadas por los ojos humanos. Para Shipman esto significa que si bien los perros domésticos fueron hechos por los humanos, a su vez, el humano actual fue hecho por el perro doméstico'

\footnotetext{
${ }^{4}$ ROMERO, J., Jane Goodall: Una visión crítica, en La Mujer en la Historia de la Ciencia (2006) 75-76. 7

${ }^{5}$ ROMERO, J. (2006), Op. Cit. 72.

${ }^{6}$ RUIZ, M. Humano y chimpancé comparten el 99\% del ADN, en El País:

https://elpais.com/diario/2005/09/01/sociedad/1125525601_850215.html, [Última consulta: 10 de diciembre de 2020]

${ }^{7}$ MEDIAVILLA, D. Primer caso de comunicación entre humanos y animales salvajes, en El País:

https://elpais.com/elpais/2016/07/21/ciencia/1469112502_711822.html [Última consulta: 11 de diciembre de 2020]

${ }^{8}$ RABINOVICH-BERKMAN, R. ¿Contratos con otras especies? en Pensar en Derecho, Año 5, No 12 (2018), 102-105.

${ }^{9}$ RABINOVICH-BERKMAN, R. (2018), Op. Cit. 105.

132 Derecho Animal. Forum of Animal Law Studies, vol. 12/2
} 
Rabinovic-Berkman incluso va más allá. Sostiene que existen similitudes entre las estructuras políticas, jurídicas y sociales de los lobos y los humanos, las que se expresaban en relaciones de admiración y respeto frente a las estructuras jerárquicas en que se organizaban estos cánidos, las que eran imitadas por los grupos humanos -por ejemplo las monarquías-. Es por eso que en los pueblos nórdicos y germánicos se ha detectado desde tiempos inmemoriales una veneración hacia la figura del lobo ${ }^{10}$.

Otro caso paradigmático se manifiesta entre humanos y delfines, con una relación que data desde la Antigua Grecia. La palabra delfín deriva del griego "delfis" -que hace referencia al útero de los mamíferos-, y también a la palabra "adelfos", que significa hermano. Existe así una noción de hermandad entre el humano y el delfín para la cultura griega. Es el romano Aeliano quien en su obra "Sobre la idiosincrasia de los animales" rescata referencias hacia los delfines a propósito de las comunicaciones entre ellos y los pescadores de las Polis de Poroselene y Eubea. Recibían nombres, convivían con los pescadores y sus familias, y colaboraban en los procesos de pesca la que era repartida, generando una verdadera relación de entendimiento mutuo $^{11}$.

En tiempos presentes esto se refleja en las toninas de la Patagonia chilena y argentina. En el Canal de Chacao, cuando los transbordadores realizan el viaje para acceder a la Isla de Chiloé, es muy común ver la presencia de delfines chilenos que juegan y hacen piruetas. Esto también pasa con el delfín patagónico, conocido también como "panda de mar", cuya presencia se encuentra desde el sur de Buenos Aires hasta el Estrecho de Magallanes.

Otra situación muy interesante respecto a esta relación se genera en la localidad de Laguna, al sur de Brasil. En este sentido, los delfines trabajan y colaboran con los pescadores del lugar acarreando cardúmenes hacia ellos, tradición que tiene una data de 120 años aproximadamente, como consta en una carta del siglo $\mathrm{XIX}^{12}$

Luke McNally del Theoretical Ecology Research Group, sostiene que durante los años 70' la demanda por interacciones sociales complejas llevó a los delfines a evolucionar cognitivamente ${ }^{13}$. India fue incluso más allá, al ser el primer país del mundo en reconocer a los delfines y a otros cetáceos como personas no humanas en el año $2013^{14}$.

Las belugas también han sido observadas socializando con humanos. Por ejemplo, recientemente la revista National Geographic dedicó un artículo a la experiencia que un marinero llamado Alon Kowen tuvo con una beluga, con la que jugó en el océano con un balón de rugby en los mares del Polo Sur, registro que el aludido había compartido en su red social de Facebook ${ }^{15}$.

Otra experiencia de convivencia humano-animal se ha verificado en los bosques del Parque Nacional Virunga, en la República Democrática del Congo. En dicho lugar, donde la caza furtiva pone en peligro la subsistencia de los gorilas que allí habitan, estas especies han sido capaces de entablar relaciones de cariño y compañerismo con los guardabosques que los cuidan. Tanto es así que se les ha visto posando juntos en fotografías, donde aparecen abrazados y felices ${ }^{16}$. Se ha detectado por estudios científicos que los canguros también se pueden comunicar con los humanos. A través de un estudio de la Universidad de Sydney, se demostró que son capaces de "hablar" para alertar sus problemas, esto a través de un contacto visual directo e insistente con los humanos. Así es como la Doctora Alexandra Green, investigadora de la Escuela de Ciencias Veterinarias de Sydney de la misma Universidad pudo comprobar esto, a través de un experimento en el que dejaron una caja para que fuese abierta por un canguro, y al no poder hacerlo, les pedían ayuda a través de su insistente mirar. A su vez, el Doctor Allan McElligott de la Universidad de Roehampton, que dirigió este proyecto de investigación, ha sostenido que no sólo se comunican por su mirada, sino también utilizando sus patas frontales o su hocico para señalar sus objetivos ${ }^{17}$.

Finalmente, un dato importante respecto a la relación entre perros y humanos. Según un reciente estudio de The Royal Society, estos son capaces de reconocer palabras, aún cuando estas sean dichas por desconocidos. Por lo tanto, pueden entender fonemas humanos independiente de la cercanía del interlocutor. Un equipo de la Universidad de Sussex probó lo anterior documentando la experiencia de 70 perros que

\footnotetext{
${ }^{10}$ RABINOVICH-BERKMAN, R. (2018), Op. Cit. 107.

${ }^{11}$ RABINOVICH-BERKMAN, R. (2018), Op. Cit. 108-110.

12 RABINOVICH-BERKMAN, R. (2018), Op. Cit. 105-113.

${ }^{13}$ RABINOVICH-BERKMAN, Ricardo (2018), Op. Cit. 113.

${ }^{14}$ ZÁRATE, C. Un Nuevo Estatus Jurídico para los Animales No Humanos (Santiago de Chile, 2020) 28 y 29.

${ }^{15}$ NATIONAL GEOGRAPHIC. Beluga juega rugby con un marinero en medio del océano", en National Geographic en Español: https://www.ngenespanol.com/animales/beluga-juega-rugby-marinero-oceano/ [Última consulta: 15 de diciembre de 2020]

${ }^{16}$ INFOBAE. Los gorilas que posaron con un guardabosques para una selfie como si fueren humanos y que se hicieron virales", en INFOBAE: https://www.infobae.com/america/mundo/2019/04/20/los-gorilas-que-posaron-con-un-guardabosques-para-una-selfiecomo-si-fueran-humanos-y-que-se-hicieron-virales/ [Última consulta: 15 de diciembre de 2020]

17 FISCHER, A. Los Canguros intentan comunicarse con los humanos para pedir ayuda, revela un estudio, en https://www.ngenespanol.com/animales/los-canguros-pueden-comunicarse-con-humanos-revela-un-estudio/ [Última consulta: 18 de diciembre de 2020]
} 
escucharon a una treintena de humanos que pronunciaron palabras que en apariencia ellos no entenderían. Determinaron que hay fonemas que de todas maneras comprendían, siendo un factor común entre ellos. Incluso se ha logrado comprobar que otros animales como chinchillas y ratas también pueden entender fonemas, pero con un entrenamiento previo ${ }^{18}$.

\section{La colaboración entre Animales No Humanos de la misma especie}

Entre especies se han detectado formas violentas de resolver conflictos, con el fin de demostrar la primacía de unos sobre otros, principalmente por factores territoriales o alimenticios. Por ejemplo, dentro de las investigaciones llevadas por Jane Gooddall a través de la observación del comportamiento de los chimpancés, detectó actos de canibalismo, luchas de patrullas que buscaban cuidar sus territorios, asesinatos de invasores, ataques sexuales a hembras y secuestros de sus crías, e incluso pudo documentar muy bien una guerra existente entre dos grupos, que duró cuatro años y terminó el año 1978 con la extinción total de una de las comunidades beligerantes ${ }^{19}$, conocida como la Guerra de los chimpancés de Gombe.

Reafirma lo expuesto Rabinovic-Berkman, quien asegura que los Grandes Simios suelen ser violentos entre ellos en algunos casos. Eso si, destaca que en el caso de chimpancés y bonobos suelen ser criaturas más dialogantes, de hecho, estos últimos suelen resolver sus conflictos a través del sexo ${ }^{20}$. Hay características comunes a los Grandes Simios, resaltándose el cuidado de los débiles, pequeños y enfermos de la comunidad, mediante el rechazo de conductas abusivas y a monopolios sexuales, tendiendo al bien común, independiente de los liderazgos ${ }^{21}$

Entre los Grandes Simios se han podido observar, además, comportamientos sociales comunitarios con connotaciones rituales, permitiéndonos deducir que el sufrimiento animal también puede manifestarse psíquica y emocionalmente, lo que demuestran a través de sus reacciones frente a situaciones como la muerte. Por lo tanto, tienen conciencia del fin de la vida. Para sostener la premisa anterior, se han estudiado distintas prácticas funerarias en grupos de gorilas de espalda plateada. Tres verdaderos funerales fueron grabados por primatólogos del Dian Fossey Gorilla Fund de Ruanda, donde se aprecia a los primates llorando la muerte de miembros de su familia y líderes de su comunidad, por ejemplo, la muerte del macho alfa, llamado Titus. Rodeaban el cuerpo del gorila fallecido, pasando incluso la noche con él. Se constató incluso el fenómeno conocido como "lactancia de consuelo", cuando un primate llamado Segasira se inclinó a mamar el pecho de su madre fallecida, a pesar de haber sido destetado, consiguiendo así calmarse por la liberación de oxitocina ${ }^{22}$.

Además de lo anterior, es necesario tener en consideración que las dinámicas funerarias ya habían sido estudiadas por las observaciones realizadas por Jane Goodall a los chimpancés de Gombe, a propósito de la muerte de las chimpancés que bautizó como Flame, Flint y Flo ${ }^{23}$.

Este tipo de comportamientos se constata también en otros primates, por ejemplo en el caso de investigadores de la Universidad de Saint Andrews de Escocia, que estudiaron el comportamiento de un grupo de chimpancés en el "Chimfunshi Wildlife Orphanage Trust" en Zambia. Ante la muerte de un miembro del grupo llamado Thomas, los otros primates reaccionaron visitándolo en varias oportunidades, limpiando su cuerpo de restos de comida y rodeándolo en círculos. Cuando se acercó la madre, Zoe, la dejaron sola velando al cadáver. Ésta trataba de asimilar la muerte de su hijo introduciéndole hierba dentro de su boca e inspeccionando sus dientes ${ }^{24}$.

Otro tipo de comportamientos comunitarios en los animales se ha observado mientras comen. A través de la presencia de un robot espía en una comunidad de gorilas ugandeses en el marco del proyecto Nature: Spy in the Wild 2, se descubrió que ellos cantan al unísono a la hora de cenar ${ }^{25}$. ¿Demostrarán ellos de esta manera el júbilo y la alegría que sienten cuando comen? Al menos, eso parece mientras realizan esta curiosa costumbre.

\footnotetext{
${ }^{18}$ NATIONAL GEOGRAPHIC, Los perros reconocen palabras aunque las digan desconocidos, en National Geographic en Español: https://www.ngenespanol.com/animales/perros-reconocen-palabras-aunque-digan-desconocidos/ [Última consulta: 18 de diciembre de 2020]

${ }^{19}$ ROMERO, J. (2006), Op. Cit. 73.

${ }^{20}$ RABINOVICH-BERKMAN, R., Cetera Animalia. A partir del “fallo Sandra en La Ley, doctrina judicial (2015) 5.

${ }^{21}$ RABINOVICH-BERKMAN, R. (2015), Op. Cit. 6.

22 SALAS, J. Los tres "funerales" que demuestran la tristeza de los gorilas, en el País:

https://elpais.com/elpais/2019/04/04/ciencia/1554378154_099642.html [Última consulta: 12 de diciembre de 2020]

${ }^{23}$ GOODALL, J., 60 Años en Gombe (Almeria, 2019). 52-53.

${ }^{24}$ HERREROS, P., Descubren nuevo ritual funerario en chimpancés, en El Mundo:

https://www.elmundo.es/blogs/elmundo/yomono/2017/03/25/descubren-un-nuevo-ritual-funerario-en.html [Última consulta: 18 de diciembre de 2020]

${ }^{25}$ FISCHER, A. Un robot espía se cuela a una manada de gorilas y descubre que cantan mientras cenan, en National Geographic en español: https://www.ngenespanol.com/animales/robot-capta-a-gorilas-cantando-a-la-hora-de-la-cena/ [Última consulta: 18 de diciembre de 2020]
} 
Existe además comunicación en los murciélagos, quienes conversan vocalmente ciertos temas comunes, por ejemplo, respecto al sexo, al sueño o la comida. Así ha asegurado el neuroecólogo de la Universidad de Tel Aviv en Israel y director del proyecto GPS-BAT Yossi Yovel ${ }^{26}$. Además, han determinado que los murciélagos son capaces de orientarse a través de puntos de referencia y mapas cognitivos mentales tal como hacemos los seres humanos. En efecto, Mirjam Knrörnschild, ecologista de comportamiento animal en el Museo de Historia Natural de Berlín y directora del proyecto Cutsong, se ha dedicado a estudiar el sistema comunicativo de los murciélagos, señalando que son capaces de desarrollar dialectos comunes, adquiridos culturalmente, produciendo un verdadero proceso de especiación ${ }^{27}$.

En atención a lo anterior y tomando como ejemplo a una de las especies de Grandes Simios más cercanas a los seres humanos en aspectos evolutivos, los bonobos, cabe destacar que existen estudios que aseguran que poseen también un lenguaje propio, muy parecido al de los bebés humanos. El estudio liderado por Zanna Clay de la Escuela de Psicología de la Universidad de Birmingham ha concluido que los bonobos se comunican a través de una especie de píos, por medio de los cuales hacen fluir sus ideas y necesidades comunes $^{28}$, o que fue logrado a través del estudio y observación directa de estas especies en su hábitat natural, en la República Democrática del Congo.

También han desarrollado un elaborado sistema de caza y alimentación fundado en la cooperación mutua de los grupos, lo que se evidencia en la investigación liderada por Liran Samuni y Martin Surbek, de la Universidad de Harvard, quienes estudiaron dos grupos de bonobos de la República Democrática del Congo, a quienes siguieron por 5 años por 57 kilómetros cuadrados de bosques, durante sus cacerías, detectando diferencias culturales en ambos grupos que se conformaban fundamentalmente en su forma de caza y sus especies predilectas ${ }^{29}$.

\section{La colaboración entre Animales No Humanos de distintas especies}

Existen experiencias de colaboración entre distintas especies, donde se ha podido constatar que las necesidades, afectos y alianzas están presentes, ya sea con fines de supervivencia o de mutuo apoyo para un beneficio común. En la biología este fenómeno es conocido como simbiosis, la que se manifiesta a través del mutualismo, en el cual todos los seres vivos participantes de un proceso colaborativo obtienen beneficios ${ }^{30}, \mathrm{y}$ en el comensalismo, en que sólo uno de los actores del proceso asociativo obtiene un beneficio, no trayendo efecto alguno al resto de los seres vivos ${ }^{31}$.

Entre los animales no humanos que han desarrollado relaciones asociativas se destacan los Grandes Simios, quienes son capaces de comunicarse entre sí a través de gestos y expresiones, las que son comprendidas, independiente de la especie de simio a la que pertenecen. Esto se ha estudiado con detalle en el caso de los bonobos y los chimpancés, a través de una investigación realizada por la Universidad de Saint Andrews en conjunto con las Universidades de Kyoto y de York, comprobando que existen más de 2300 gestos de bonobos los que en su mayoría son compartidos también por los chimpancés, gozando de significados comunes ${ }^{32}$.

Hay un curioso caso en el mundo marino de este tipo de relaciones colaborativas animales, que se refiere al nexo entre las rémoras y los tiburones. Los primeros suelen viajar sujetos a los segundos, por ello se dice que son los más fieles compañeros de los tiburones. En este caso, la compañía de la rémora para el tiburón es indiferente, ya que no le genera beneficios pero tampoco consecuencias negativas, sin perjuicio de detectarse irritaciones en algunos $\operatorname{casos}^{33}$. La rémora, en cambio, se siente protegida por el depredador. Es decir, estamos frente a una relación simbiótica comensalista.

\footnotetext{
${ }^{26}$ HERNÁNDEZ, J. Los murciélagos “conversan” sobre sexo, sueño y comida. en El País: https://elpais.com/ciencia/2020-12-08/losmurcielagos-conversan-sobre-sexo-sueno-y-comida.html [Última consulta: 14 de diciembre de 2020]

${ }^{27}$ HERNÁNDEZ, J. (2020), Op. Cit.

${ }^{28} \mathrm{CNN}$. Los bonobos hablan como los bebés humanos, según estudios, en https://cnnespanol.cnn.com/2015/08/04/segun-estudio-losbonobos-hablan-de-la-misma-forma-que-lo-hacen-nuestros-bebes/ [Última consulta: 15 de diciembre de 2020]

${ }^{29}$ NOTICIAS DE LA CIENCIA Y LA TECNOLOGÍA. Diferencia cultural entre dos comunidades vecinas de bonobos, en https://noticiasdelaciencia.com/art/39400/diferencia-cultural-entre-dos-comunidades-vecinas-de-bonobos, [Última consulta: 15 de diciembre de 2020]

${ }^{30}$ CORDERO, M. y MARTÍNEZ, A. El parasitismo y otras asociaciones biológicas. Parásitos y hospedadores, en Parasitología Veterinaria, Madrid (1999). 23-25

${ }^{31}$ CORDERO, M. y MARTÍNEZ, A. (1999). 26

${ }^{32}$ RTVE. Chimpancés y bonobos pueden entenderse con gestos, en https://www.rtve.es/noticias/20180228/chimpances-bonobospueden-entenderse-gestos/1686264.shtml [disponible el 16 de diciembre de 2020]

${ }_{33}$ BOEGE, K. y DEL VAL, E. Bichos vemos relaciones no sabemos: diversidad e importancia de las interacciones bióticas en Revista Ciencias UNAM, Ciudad de México. (2011) 6.
} 
Hay otros animales marinos que colaboran entre sí, por ejemplo, algunas especies de peces, anémonas y crustáceos que se dedican a limpiar de parásitos, tejidos muertos y restos de comida a otros peces, alimentándose de esos desperdicios ${ }^{34}$. En este caso la relación es simbiótica mutualista.

Otros ejemplos de relaciones interespecie encontramos en hipopótamos y pájaros, rinocerontes y búfalos, ranas y tarántulas, hormigas y pulgones ${ }^{35}$, cigueñas, garzas y cocodrilos, pájaros carpinteros y hormigas ${ }^{36}$, entre otros. A pesar de que estamos frente a colaboraciones animales que no gozan de estructuras comunicativas complejas, sin duda existe una comunicación y una cooperación relevante, reflejándonos una increíble diversidad de redes y relaciones que a través de años de estudios e investigaciones científicas la humanidad recién está logrando comprender.

\section{Sobre la necesidad de proteger jurídicamente la colaboración animal no humana}

Como cuestión previa, consideraremos la visión manifestada por el doctor Eugenio Raúl Zaffaroni, quien, en las Jornadas de Concientización sobre Legislación Animal de la Legislatura de la Ciudad Autónoma de Buenos Aires expuso que no ve posible la realización de los Derechos Humanos sin reconocer como sujetos de derechos a las demás especies, resultándole difícil hablar de derechos animales siendo él mismo un animal $^{37}$

Esta particular visión también la ha expresado en su obra "La Pachamama y el Humano", resaltando la ambivalencia que el humano ha tenido con el resto de los animales a lo largo de la historia, principalmente por la influencia religiosa, donde los seres humanos buscaban diferenciarse de los animales y asimilarse con lo divino, de donde nace una suerte de jerarquización, que a su vez fue potenciada por el pensamiento positivista del siglo XIX y XX ${ }^{38}$.

Sostiene, por lo tanto, que el replanteamiento de la cuestión de los derechos de entes no humanos se ha hecho presente en las sorpresas que ha dejado el neoconstitucionalismo latinoamericano, en especial en las constituciones de Ecuador de 2008 y de Bolivia el $2009^{39}$.

En efecto, en Chile, que tiene un debate abierto respecto a su cambio constitucional, ya existe un proyecto de ley que busca modificar el Código Civil para que los animales sean declarados seres sintientes, dejando de ser considerados bienes muebles, lo que a juicio del Presidente de la Comisión de Constitución de la Cámara de Diputadas y Diputados de Chile, Matías Walker, podría ser la antesala de un bonito debate que podría generarse en la futura Convención Constitucional ${ }^{40}$.

No obstante, la activista pro-animal Patricia Cocas, sostiene que esto no significa que sean sujetos de derecho, porque el hecho de que sean seres sintientes no cambia el estatus sobre derechos de propiedad o la comercialización animal, sólo indica que no se les puede maltratar ${ }^{41}$.

Lo anterior se contrapone a las perspectivas planteadas por el doctor Zaffaroni, toda vez que, a propósito del delito de maltrato de animales, expresa que el bien jurídico a proteger es el derecho del propio animal a no ser objeto de la crueldad humana, siendo necesario reconocer su carácter de sujeto de derechos ${ }^{42}$. Visión que particularmente compartimos.

El mismo Zaffaroni, citando a Singer, en su obra "Liberación Animal" del año 1975, sostiene que la negación de los derechos del animal no humano constituye un especismo paralelo al racismo, puesto que la negación del derecho por el sólo hecho de pertenecer a otra especie o tener alas no dista mucho de hacerlo por el color de piel. Luego afirma que si bien es cierto que el animal tiene menor inteligencia que el humano, no es menos cierto que hay humanos que no tienen inteligencia o que están dotados de una inteligencia menor que el animal, y nada autoriza a que por esto se les trate cruelmente o se experimente con ellos ${ }^{43}$.

\footnotetext{
${ }^{34}$ WESTHOFF, R. Amigos inesperados: 6 increíbles relaciones simbióticas en la naturaleza”, en El Definido: https://eldefinido.cl/actualidad/mundo/7618/Amigos-inesperados-6-increibles-relaciones-simbioticas-en-la-naturaleza/ [Última consulta: 20 de diciembre de 2020]

${ }^{35}$ EL DEFINIDO (2016), Op. Cit.

${ }^{36}$ MISSE, J. Los pactos más extraños del mundo animal, en La Vanguardia:

https://www.lavanguardia.com/natural/20160321/40592697210/simbiosis-pactos-animales.html [Última consulta:16 de diciembre de 2020]

${ }^{37}$ LORA, L., Problemas actuales en la consideración socio-jurídica de los animales no humanos como sujetos de derecho, en Nuevos debates en filosofia y ciencia política (Mar del Plata, 2015) 9.

${ }^{38}$ ZAFFARONI, E., La Pachamama y el Humano (Buenos Aires, 2017). 23-28.

${ }^{39}$ ZAFFARONI, E. (2017), Op. Cit. 23.

${ }^{40} 24$ HORAS. Proyecto busca que animales sean declarados "seres vivientes y sintientes" en Chile, en 24 Horas: https://www.24horas.cl/nacional/proyecto-busca-que-animales-sean-declarados-seres-vivientes-y-sintientes-en-chile-4560426 [Última consulta: 20 de diciembre de 2020]

${ }^{41} 24$ HORAS (2020), Op. Cit.

${ }^{42}$ ZAFFARONI, E. (2017), Op. Cit. 54.

${ }^{43}$ ZAFFARONI, E. (2017), Op. Cit. 72-73.
}

136 Derecho Animal. Forum of Animal Law Studies, vol. 12/2 
En la misma linea de Zaffaroni y Singer, Rabinovich-Berkman también sostiene que la consideración jurídica de los animales ha ido variando a través de los siglos, como también ha pasado con los esclavos y las mujeres. Por ejemplo, en Roma se daba poca importancia al color de piel, al punto de que el emperador Septimio Severo era un bereber africano. A su vez, para los griegos la homosexualidad era un tema de poca importancia, y las primeras representaciones prehistóricas de estatuillas humanas son sólo de mujeres, por lo que la Humanidad se veía representada de forma femenina ${ }^{44}$.

De hecho Singer, en su obra "Liberación Animal", sostiene que se puede notar un paralelismo en los argumentos esgrimidos antiguamente para negar derechos a las mujeres y los que se emplean para negárselos a los animales no humanos, lo que ha sido denunciado por movimientos ecofeministas ${ }^{45}$. Por ejemplo, en Chile hasta 1989 se consideró incapaz relativa a la mujer casada en sociedad conyugal. Algo que en el siglo XXI sería una garrafal injusticia, fue una realidad que limitaba la vida de muchas mujeres chilenas, subyugadas a la voluntad patriarcal.

Desde una reafirmación práctica, no podemos pasar por alto la resolución de fecha 29 de abril de 2015 dictada por el Juzgado $N^{o} 15$, Secretaría Única del Fuero Penal Contravencional y de Faltas del Poder Judicial de la Ciudad de Buenos Aires, respecto al caso de la orangutana Sandra, cautiva en el Zoológico de Buenos Aires. En este fallo se reconoce expresamente que ella es un sujeto de derechos que se asemeja a un incapaz de hecho ${ }^{46}$.

Por lo tanto, es perfectamente asimilable la condición de los animales no humanos a la de los incapaces. El que se les considere sujetos de derechos responde a un cambio de mentalidad en que la Humanidad acepte su realidad animal, manifestada en aspectos sensitivos comunes. en especial en aspectos sensibles y emocionales, lo que reafirmamos, además de considerar el fallo señalado en el párrafo anterior, en la siguiente reflexión de Zaffaroni:

"El argumento de que no es admisible el reconocimiento de los derechos porque no puede exigirlos (ejercer las acciones, hacerse oír judicialmente) no se sostiene, porque son muchos los humanos que carecen de capacidad de lenguaje (oligofrénicos profundos, fetos) o que nunca la tendrán (descerebrados, dementes en los últimos estadios) y, sin embargo, a nadie se le ocurre negarles este carácter, so pena de caer en la tesis genocida de las vidas sin valor vital de una de las cúspides del pensamiento penal, considerada por la mayoría como un pecado de ancianidad o algo parecido (...) Cabe observar que la vigente ley positiva argentina reconoce al animal como titular del bien jurídico en el delito de maltrato, asignándole el carácter de víctima, lo cual, considerando la fecha de esta ley -en la que no era aún materia de discusión tan viva como en el presente- constituye una intuición sumamente interesante." 47

Siguiendo lo anterior, Bentham sostenía que la capacidad de sufrimiento es la característica básica que le otorga a un ser el derecho a una consideración igual, siendo la capacidad de sufrir y de disfrutar un requisito para tener cualquier otro interés que satisfacer ${ }^{48}$.

Uno de los autores que ha contribuido de una forma notable a este cambio de paradigma es Valerio Pocar, a través de obra titulada "Los animales no humanos. Por una sociología de los derechos", cuya traducción a la lengua castellana fue llevada a cabo por la doctora Laura Lora.

De lo anterior, es sumamente destacable que la aproximación que hace Pocar a este tema es de carácter sociológico-jurídica, en base a determinar si en la sociedad humana se acepta el reconocimiento de los derechos de los animales y en qué medida tal opinión se traduce en normas jurídicas que regulan la relación entre humanos y animales ${ }^{49}$. Mirando esta premisa desde una perspectiva sociológica, existen regulaciones que buscan garantizar la sana cooperación entre los animales y humanos, equiparando sus condiciones y evitando abusos, tal como ocurre en otras ramas del derecho, como en el derecho del trabajo o del consumidor.

Por ejemplo, en el caso argentino podemos mencionar la Ley $\mathrm{N}^{\circ} 14.346$, sobre Protección a los animales, la Ley N ${ }^{\circ} 1.426$ de la Ciudad Autónoma de Buenos Aires, el Decreto Reglamentario de la Ley No 13.879, sobre Prohibición en las dependencias oficiales de la práctica del sacrificio de perros y gatos, la Ley $\mathrm{N}^{\mathrm{o}} 2.786$ sobre Prohibición a malos tratos de animales -del año 1891, por cierto-, y los artículos 41 y 43 de la Constitución Nacional de la República Argentina. En el caso chileno, podemos destacar la Ley N 20.380 sobre Protección de Animales y la Ley N 21.020 sobre Tenencia Responsable de Mascotas y Animales de

\footnotetext{
${ }^{44}$ RABINOVICH-BERKMAN, R. (2015), Op. Cit. 6.

${ }^{45}$ ZAFFARONI, E. (2017), Op. Cit. 72.

${ }^{46}$ LORA, L. (2015), Op. Cit. 10-11.

${ }^{47}$ ZAFFARONI, E. (2017), Op. Cit. 54-55.

48 SINGER, P., Liberación Animal (Barcelona, 2018). 23-24.

${ }^{49}$ LORA, L. (2015), Op. Cit. 2-3.
} 
Compañía, conocida también como "Ley Cholito". En todas estas normativas existe un núcleo esencial, basado en evitar el sufrimiento animal, y en definitiva, entregar dignidad reconociendo una igualdad entre los seres sencientes, basada en el evitar expresiones de dolor y crueldad a través del derecho.

Hay, por lo tanto, una premisa de igualdad, basada en la capacidad en común que tienen este tipo de seres: La capacidad de sufrir. A esta circunstancia también alude Peter Singer para sostener la existencia de un principio de igualdad entre los humanos y otros animales, aludiendo que no se puede limitar sus derechos aludiendo a la inteligencia y/o raciocinio, lo que sería tan arbitrario como el racismo o el sexismo ${ }^{50}$.

A partir de lo anterior, Pocar sostiene que todos los seres sencientes -como llama a los seres capaces de experimentar placer y sufrimiento- son titulares de derechos, invitando a reconocer sus derechos fundamentales, adoptando las tendencias animalistas, desmarcándose de las corrientes ecologistas ${ }^{51}$ puesto que se plantean desde el antropocentrismo, que considera a los animales no humanos como un objeto del derecho y no como sujetos ${ }^{52}$.

Aquí sin embargo hay que realizar una importante salvedad: Pocar sostiene que la consecuencia de considerar a los animales no humanos como objetos de derechos es su protección pensándolos como género o especie, más no como sujetos individuales, por lo que la reglamentación actual se plantea como derechos colectivos, más no individuales ${ }^{53}$. Por ello, con estas normas ya podríamos proteger derechos de carácter colectivo derivados de la cooperación animal. No obstante lo anterior, creemos necesario superar la visión que considera a los animales como cosas, promoviendo su calidad de sujetos y titulares de derechos, buscando evitar su sufrimiento y fomentar su desarrollo digno, acorde a su condición viviente.

No debe sorprendernos entonces que exista jurisprudencia que si bien consideran al animal objeto de derecho resaltan componentes comunitarios como argumentos para protegerlos, por ejemplo en el caso de la Chimpancé Cecilia en el fallo de la Cámara de Apelaciones en lo Penal, Contravencional y de Faltas de fecha 07 de septiembre de 2015, señalando que pertenece al patrimonio colectivo y cultural de la comunidad, vulnerándose así el artículo 41 de la Constitución Nacional de la República Argentina ${ }^{54}$.

Desde otra perspectiva, en otra resolución de fecha 12 de diciembre de 2016, a propósito del caso de la orangutana Sandra, se destaca el hecho de que la ley 14.346 consagra el status de víctima del animal no humano, y que en consecuencia, se trata de personas que no se pueden expresar. Aquí el concepto de persona puede tener distintas acepciones, como pasa por ejemplo con las personas jurídicas, las que no tienen que ver con la personalidad en un sentido metafísico ni moral, a diferencia de los animales, que científicamente no son $\operatorname{cosas}^{55}$.

Tomaremos en consideración este argumento para decir que las personas jurídicas son cosas inmateriales que no tienen una existencia física ni biológica, ni tampoco sentimientos, emociones o pensamientos, tratándose de ficciones jurídicas, como bien las caracteriza el Código Civil chileno en su artículo 545: "Personas ficticias". Si una ficción jurídica puede tener derechos, casi como una persona natural, ¿Por qué no se puede reconocer como persona a un animal no humano, que tiene más en común con los humanos que una abstracción intelectual?

En el plano internacional, también hay normativas analizables desde el prisma de la protección a la cooperación animal. Volvemos así al llamado "Proyecto Gran Simio", y a su planteamiento igualitarista entre humanos y Grandes Simios como de sujetos de derechos, a través de darle validez a la llamada "Declaración de los Grandes Simios Antropoideos", profundizando y superando la "Declaración Universal de los Derechos del Animal" de 1977.

Conforme a este proyecto son muchas las voces que exigen a UNESCO que reconozca a los Grandes Simios como Patrimonio Vivo de la Humanidad, promulgando una Declaración de Derechos de los Grandes Simios que proteja las poblaciones de Grandes Simios libres, sus hábitat, a los indígenas locales que se relacionan y conviven con ellos, entre otros aspectos. Personalidades como Kofi Annan, el antropólogo Richard Leakey y el genetista Richard Goodman han sido favorables a esta idea, incluso promoviendo que se les considere dentro del género homo ${ }^{56}$. UNESCO, en todo caso, también ha realizado acciones para protegerlos, como el Proyecto para la Supervivencia de los Grandes Simios, conocido por su sigla GRASP.

\footnotetext{
${ }^{50}$ SINGER, P., (2018). Op. Cit. 25.

${ }^{51}$ LORA, L. (2015), Op. Cit. 5 y 6.

${ }^{52}$ LORA, L. (2015), Op. Cit. 9.

${ }^{53}$ LORA, L. (2015), Op. Cit. 10.

${ }^{54}$ LORA, L. (2018), Op. Cit. 8

${ }^{55}$ LORA, L. (2018), Op. Cit. 8.

56 POZAS, P. La UNESCO debe declarar a los grandes simios "Patrimonio Vivo de la Humanidad", en El Diario: https://www.eldiario.es/caballodenietzsche/grandes-simios-patrimonios-vivos-

humanidad_132_2278518.html\#: :text=S\%C3\%ADguelo\%20en\%20redes-

,La\%20Unesco\%20debe\%20declarar\%20a\%20los\%20grandes,Patrimonio\%20Vivo\%20de\%201a\%20Humanidad'\&text=Los\%20gra

138 Derecho Animal. Forum of Animal Law Studies, vol. 12/2
} 
En todo caso, la "Declaración Universal de los Derechos del Animal" de 1977, reconocido por UNESCO y ONU, también tiene aspectos destacables respecto a la protección de los derechos de los animales no humanos, incluyendo los aspectos asociativos y comunitarios. Su artículo 11 establece que la muerte innecesaria de un animal es un biocidio, es decir, un atentado contra la vida. También establece en su artículo 12 que todo acto que implique la muerte de una gran cantidad de animales en estado salvaje constituye un genocidio, en especial la contaminación y la destrucción del ambiente natural.

Que haya usado el término genocidio no es algo menor, toda vez que el Estatuto de Roma de la Corte Penal Internacional en su artículo sexto, señala que el genocidio se perpetra con la intención de destruir total o parcialmente a un grupo nacional, étnico, racial o religioso, es decir, un conjunto de seres humanos agrupados por una característica o situación particular, lo que también es posible apreciar en algunas especies animales no humanas, como hemos ejemplificado en párrafos anteriores. ¿Es posible entonces proteger a los animales en su conjunto con estas normativas que declaran genocidio la muerte masiva de especies?

Para lograr una respuesta positiva realista necesitamos cambiar la forma de ver a los animales no humanos, incluso en sus derechos sociales y colectivos, lo que va más allá de si las interpretaciones de estos instrumentos puedan dar cabida a su protección.

De esta manera, desde España se anunció a principios del año pasado que el Ministerio de Derechos Sociales incluirá la protección a los animales, lo que se concreta por el Real Decreto 1112/2020 de fecha 15 de diciembre de 2020, que le da un contenido práctico y presupuestario en conjunto con otras medidas para la protección de derechos sociales de diversa índole ${ }^{57}$.

Por lo tanto, que la protección de los animales no humanos reciba un tratamiento similar a la de otros derechos sociales propiamente humanos, nos refleja que existe un afán igualitario, lo que se realza con que sea el Ministerio de Derechos Sociales quien levante esta novedosa propuesta.

Profundizando en lo anterior, a continuación es importante analizar, en primer lugar, cuáles serían sus derechos fundamentales de carácter colectivo susceptibles de reconocimiento y protección, así como los argumentos y consideraciones que así lo justificarían.

\section{Derechos fundamentales colectivos y animales no humanos. Argumentos y consideraciones en favor de su reconocimiento}

Ya habiendo profundizado en aspectos doctrinarios vinculados a la sociología, la etología y también al derecho, analizaremos la susceptibilidad del reconocimiento de Derechos Fundamentales de los animales no humanos en un plano colectivo, considerando a estos seres sencientes como Sujetos de Derecho, lo que incluiría garantizar sus relaciones sociales en todos los aspectos, inclusive la comunicación interespecie.

Demostraremos a continuación que variados argumentos y consideraciones aportados por científicos y académicos que destacan la importancia de estas interacciones para la supervivencia y desarrollo evolutivo de estas criaturas.

A raíz de lo anterior, nuestro análisis se sitúa netamente en el plano de los derechos colectivos, sobre todo desde el prisma de la colaboración y la comunicación entre animales no humanos.

\subsection{Derechos Fundamentales Colectivos y Animales No Humanos}

Para este punto consideraremos los principios de la ecología profunda, sosteniendo que la naturaleza tiene una personería y una titularidad de derechos propios e independientes al Ser Humano ${ }^{58}$. Desde la ciencia esta idea se manifiesta por la llamada Hipótesis Gaia de James Lovelock, quien entiende que la Tierra es un ser viviente, siendo un sistema que se autorregula ${ }^{59}$. Los planteamientos de la ecología profunda son hoy adoptados por el Derecho Constitucional Latinoamericano, que recoge la idea de Gaia desde el prisma de la Pachamama ${ }^{60}$, concepto base de muchas culturas ancestrales locales.

A razón de lo anterior, toda la vida en el Planeta ha evolucionado, alcanzando desde sus inicios un desarrollo basado en relaciones colaborativas y simbióticas interespecie, aportando así a la biodiversidad. El ser humano, bajo esta lógica, no sería más que otra especie en la Tierra, y parte de ella, equiparándose así con otros animales que también son parte de este tipo de relaciones.

ndes $\% 20$ simios $\% 20$ (bonobos\%2C\%20orangutanes,siendo\%20diezmadas\%20por\%20numerosas\%20causas. [Última consulta: 20 de diciembre de 2020]

${ }^{57}$ Ver Real Decreto 1112/2020, de 15 de diciembre de 2020, Reino de España.

${ }^{58}$ ZAFFARONI, E. (2017), Op. Cit. 69.

${ }^{59}$ ZAFFARONI, E. (2017), Op. Cit. 78-80.

${ }^{60}$ ZAFFARONI, E. (2017), Op. Cit. 88-89. 
Desde el derecho, lo anterior se manifestaría logrando un reconocimiento expreso de la igualdad entre todos los seres sencientes, humanos o no. Existe aquí una clara noción de dignidad, fundamento básico y esencial para reconocer a los animales no humanos como sujetos de derecho.

De aquí surge un factor clave: el trato igualitario que debe existir entre las criaturas sensibles. Peter Singer, a pesar de criticar las posturas de De Waal en cuanto a desconocer la existencia de derechos esenciales para los animales, si resalta que reconozca la importancia del trato digno y exento de todo dolor para ellos ${ }^{61}$, que para Singer debe necesariamente manifestarse en el considerarse sujetos de derecho a los animales no humanos.

Es así como la igualdad y la dignidad son garantías básicas para el ejercicio del resto de los derechos colectivos, que según lo concluido por los estudios, observaciones e investigaciones recientes en el plano de la cooperación animal planteadas en capítulos anteriores, consideramos susceptibles de reconocimiento.

Uno de esos derechos fundamentales es el de asociación. Cabe destacar en este punto que existen opiniones comunes entre De Waal y Singer respecto a los que llaman mamíferos sociales ${ }^{62}$, reconociendo atisbos de moralidad sobre todo en los comportamientos gregarios de los Grandes Simios. De Waal concluye que incluso las raíces de la moralidad humana se encuentran en la naturaleza social compartida con otros primates inteligentes ${ }^{63}$.

La observación directa de estos comportamientos sociales ya ha sido analizada en este artículo a propósito de los estudios de la primatóloga Jane Goodall, quien constató modelos organizativos y comunicativos muy avanzados entre los chimpancés de Gombe, investigaciones que incluso han dado paso a más de doscientos artículos científicos, treinta y tres tesis doctorales, treinta libros, cientos de artículos y ciclos de conferencias ${ }^{64}$, lo que demuestra una verdadera revolución académica a partir de sus descubrimientos.

De estos estudios surge la necesidad de consagrar otro derecho colectivo primordial, al ser un presupuesto de las experiencias de cooperación animal. Nos referimos al derecho a comunicarse y expresarse.

Goodall, en efecto, ha demostrado la existencia de formas comunicativas no verbales en el caso de los chimpancés, determinando que muchos de sus aspectos conductuales relacionados con la socialización, la expresión emocional, y la satisfacción de necesidades son similares a las de los humanos, y que incluso existen variadas habilidades cognitivas que erróneamente se pensaba que eran privativas de nuestra especie, pero que en el caso de los chimpancés, también existen ${ }^{65}$.

¿A qué responde la necesidad o utilidad de reconocer la comunicación y expresión de los animales como un Derecho Fundamental? Claramente con ello protegemos una herramienta clave que les permite asociarse, detectando formas complejas de interconexión que les permiten evolucionar y adecuarse a un entorno, organizarse como especies, contactarse con otras especies a través de primitivas expresiones lingüisticas no verbales -por ejemplo en el caso de chimpancés y bonobos- y desarrollar prácticas ceremoniales y rituales. Lo anterior se resume en la necesidad de proteger una verdadera expresión cultural que incluso puede explicar nuestra propia evolución como primate pensador y lógico.

Buscando explicar el fenómeno evolutivo humano desde la observación de los grandes simios, Diamond se inclina por un desarrollo de las bases anatómicas del lenguaje hablado complejo, reconociendo que criaturas como gorilas, chimpancés y otros monos tienen la capacidad de comunicarse simbólicamente sin recurrir a la palabra hablada, siendo aún un debate abierto en el campo científico hasta qué punto puede equipararse las formas comuncativas animales a nuestro lenguaje hablado, no obstante ser indudable que estamos frente a formas de comunicaciones simbólicas ${ }^{66}$.

Desde este derecho se desprenden otros, como el derecho a tener una familia -que en la praxis se puede traducir en no ser privado de sus crías-, el derecho a vivir en su comunidad de origen y en su hábitat natural, entre otras claras manifestaciones sociales, lográndose que a través del derecho se evite la extinción de tales especies por los abusos cometidos de parte de la caza furtiva o el irresponsable desarrollo empresarial presente en los últimos siglos.

\subsection{Argumentos en favor del reconocimiento de derechos colectivos en materia animal}

No pueden protegerse jurídicamente los derechos colectivos animales sin que se establezca la obligación de los seres humanos para velar por el cumplimiento de ellos, absteniéndose de prácticas abusivas

\footnotetext{
${ }^{61}$ DE WAAL, F., Primates y Filósofos. La Evolución de la moral del simio al hombre (Barcelona, 2006). 190-191.

${ }^{62}$ DE WAAL, F. (2007), Op. Cit. 187-189.

${ }^{63}$ DE WAAL, F. (2007), Op. Cit. 133.

${ }^{64}$ GOODALL, J., (2019). Op. Cit. 73-77.

${ }^{65}$ GOODALL, J. (2019), Op. Cit. 73-75.

${ }^{66}$ DIAMOND, J. El Tercer Chimpancé. Origen y futuro del animal humano (Barcelona, 2007), 82-83.

140 Derecho Animal. Forum of Animal Law Studies, vol. 12/2
} 
y dolorosas para el resto de los animales. Reconocer la existencia de expresiones sociales y culturales complejas, aunque distintas y menos evolucionadas a las humanas, es también parte de esta obligación.

Lo anterior nace de la responsabilidad que tienen los humanos a la que hacía referencia Hans Jonas, la que emana del hecho de ser los únicos seres vivos que pueden elegir distintas alternativas de acción, en especial al verificar la vulnerabilidad de la naturaleza -por tanto a los animales y sus manifestaciones colaborativas-, aumentando tal imperativo de protección en la medida que tomamos conciencia de su destrucción, lo que llama "experiencia de vulnerabilidad" 67 .

Destacamos, en este sentido, la reflexión de Rawles en cuanto a sostener que el paso de la humanidad a la socialidad dependía de que se dieran condiciones de justicia, es decir, de una cooperación mutuamente beneficiosa entre iguales ${ }^{68}$.

DE WAAL también analiza la justicia desde el comportamiento de los simios, señalando que la aversión hacia la desigualdad existente en los humanos se puede explicar al observar el comportamiento de algunos monos, por medio de experiencias relativas al resultado de relaciones de cooperación y de acceso a los recursos, los que generan una reacción negativa, comúnmente manifestada como una protesta por parte de los individuos subordinados, y la práctica del castigo por parte de los dominantes ${ }^{69}$.

Comprendemos, pues, que las obligaciones anteriormente mencionadas son también parte de una relación cooperativa interespecie basada incluso en un instinto animal de supervivencia, dotando el ser humano de derechos a sus semejantes precisamente como una forma de apoyo recíproco.

En efecto, desde lo instintivo, Charles Darwin reflexiona a propósito de los orígenes de la moralidad lo siguiente: "Cualquier animal dotado de unos instintos sociales bien marcados, incluso el cariño parental y filial, inevitablemente adquirirá un sentido moral o conciencia tan pronto como sus facultades intelectuales hayan logrado un desarrollo tan elevado, o casi tan desarrollado como el hombre" ${ }^{\text {"70 }}$.

Existe, pues, un plano de igualdad entre todos los animales que parte de sus similitudes sobre todo sensitivas, biológicas y emocionales. Comprendiendo lo anterior, podemos rescatar los siguientes argumentos que justifican la necesidad de reconocer derechos colectivos en el ámbito animal:

a) Desde la filosofía utilitarista, Bentham sostiene que los derechos no pueden negarse a los animales puesto que ellos también sienten sensibilidad frente al dolor. En la búsqueda de este autor, resumida en buscar la mayor felicidad para todos, el reducir el dolor a los seres sensibles, lo que incluye a los animales, convoca al respeto y reconocimiento de sus derechos. En efecto, este autor soñaba con que algún día se les reconozca como sujetos de derechos ${ }^{71}$.

b) Retomando la idea de Hans Jonas respecto a la "experiencia de vulnerabilidad", cabe destacar que el mismo ser humano reconoce ser vulnerable ante una serie de situaciones, obligándose a depender de otros para poder sobrevivir ${ }^{72}$. De aquí surge la necesidad de protección ante la vulnerabilidad, factor común con otros seres sencientes. Si consideramos que el resto de los seres animados suelen estar en una desprotección mayor, podemos asimilar su condición a la de aquellos seres humanos que por sus incapacidades cognitivas, físicas o psíquicas no pueden darse a entender claramente, requiriendo por su condición el ser protegidos por la sociedad.

De lo anterior, no se puede negar la existencia de una interdependencia con otros seres de la misma u otra especie, siendo incluso parte integral de los procesos de socialización. Se detectan, de esta manera, tópicos comunes entre seres humanos y algunos animales desde la filosofía de Aristóteles y Tomás de Aquino, quienes incluso atribuían esta capacidad social al razonamiento práctico que estas especies desarrollaron, siendo una característica común, que nace de la capacidad para prever ${ }^{73}$. Alasdair MacIntyre profundiza en lo anterior al sostener que existe un conjunto de virtudes pertenecientes a las de los animales racionales y dependientes, cuyos rasgos deben ser comprendidos dentro de sus relaciones recíprocas, por lo que fenómenos como la discapacidad y dependencia se vinculan con una condición animal inicial, que llevó a los seres humanos hacia la independencia racional a través del desarrollo de este conjunto de virtudes, que comparte con otros animales ${ }^{74}$.

\footnotetext{
${ }^{67}$ ZAFFARONI, E. (2017), Op. Cit. 74.

${ }^{68}$ DE WAAL, F. (2007), Op. Cit. 28.

${ }^{69}$ DE WAAL, F. (2007), Op. Cit. 72-73.

${ }^{70}$ DE WAAL, F. (2007), Op. Cit. 39.

${ }^{71}$ ZAFFARONI, E. (2017), Op. Cit. 38.

${ }^{72}$ MACINTYRE, A., Animales Racionales y Dependientes. Por qué los seres humanos necesitamos las virtudes (Barcelona, 2001), $15-21$.

${ }^{73}$ MACINTYRE, A. (2001), Op. Cit. 20-21.

${ }^{74}$ MACINTYRE, A. (2001), Op. Cit. 19.
} 
c) Otro argumento importante para reconocerles a los animales no humanos derechos colectivos es que sus comportamientos gregarios nos sirven para entender mejor nuestra percepción, sentimientos y acciones inteligentes como humanos. Por lo anterior, De Wall sostiene que: "En el comportamiento de los humanos existe una relación muy estrecha entre empatía y compasión, y su expresión es el altruismo psicológico, por lo que es razonable asumir que las respuestas altruistas y bondadosas de otros animales, especialmente de los mamíferos, están basadas en mecanismos similares"75. Esto se puede demostrar a través de los paradigmas actuales y descubrimientos emanados de las más recientes investigaciones científicas enfocadas en el comportamiento asociativo animal, a los que ya nos hemos referido en capítulos anteriores.

Filosóficamente, existen corrientes que sostienen que la moralidad ha surgido de forma natural en nuestra especie, basado en razones evolutivas, no obstante la fragmentación actual existente en la transición de animal social a humano moral, presentándose como un fenómeno intragrupal, donde los miembros de una misma comunidad son mejor tratados que los de otras diversas, fenómeno también observable en primates en estado salvaje, siendo la moralidad misma, en definitiva, una consecuencia lógica de las tendencias cooperativas desde el comienzo de nuestra especie ${ }^{76}$.

De esta manera, Goodall ha podido determinar, en el caso de los chimpancés, que ellos habitan en sociedades complejas compuestas de cincuenta miembros aproximadamente, y que son capaces de reconocerse recíprocamente como individuos. También se trata de sociedades patriarcales, donde los machos adultos compiten por ser el alfa, además de ser agresivos y territoriales, atacando a los miembros extraños, pertenecientes a otros grupos ${ }^{77}$.

d) Existen animales que incluso han desarrollado un profundo grado de inteligencia, lenguaje, emociones y cooperación. Lo anterior tiene su justificativo precisamente en los diversos estudios que se han basado en el comportamiento de algunas especies gregarias, también en factores fisioneurológicos como el tamaño de su masa y corteza cerebrales, la demostración de sus afectos y pasiones, así como en su capacidad comunicativa, lo que demuestra la existencia de un grado de inteligencia y comprensión, lo que ocurre por ejemplo en el caso de los delfines ${ }^{78}$, o de los grandes simios, frente a los cuales DE WAAL ha señalado que existe toda una teoría de la mente primate ${ }^{79}$.

e) Finalmente, es posible detecta diferencias cromosómicas mínimas entre el Ser Humano y otras especies animales, en especial respecto de sus parientes más cercanos. En base a lo anterior, tomando nuevamente como ejemplo a los Grandes Simios, la diferencia cromosómica entre los seres humanos y chimpancés es de un $1,6 \%$, y con los gorilas es de $2,3 \%{ }^{80}$. En lo biológico, estas similitudes pueden verificarse en otros ámbitos, como el ciclo vital, la taxonomía, o la sexualidad ${ }^{81}$.

\section{Conclusiones.}

Considerando las distintas visiones científicas y académicas analizadas en este artículo, podemos justificar el reconocimiento de derechos de los animales no humanos desde un plano colectivo, lo que contribuye a superar el antropocentrismo, que ha sido la tendencia hasta ahora.

Como pudimos apreciar, hay animales no humanos que han sido capaces de comunicarse, organizarse y tener prácticas comunes, pudiendo demostrar sus sentimientos, emociones y necesidades a través de sus relaciones e interacciones sociales como miembros de una comunidad animal dotada de comportamientos sociales jerarquizados y organizados.

Por ello, nada obstaría para reconocer su dignidad y proteger de sus derechos más básicos en sus dimensiones individuales y colectivas, cumpliéndose así con las condiciones de un Animal Lógico sostenidas por Aristóteles, aunque sea de una forma distinta a la humana.

En efecto, consideramos que estas prácticas animales deben ser protegidas reconociendo sus derechos sociales y culturales de carácter colectivo, garantizando así su supervivencia como agrupación de seres sencientes. Todo lo anterior con el fin de superar los criterios especistas, los que siguen muy presentes en algunas personas que consideran a los animales objetos dignos de explotación, siendo ejemplo de ello la caza

\footnotetext{
${ }^{75}$ DE WAAL (2007), Op. Cit. 53-54.

${ }^{76}$ DE WAAL, F. (2007), Op. Cit. 81-83.

${ }^{77}$ GOODALL, J. (2019) Op. Cit. 90.

${ }^{78}$ MACINTYRE, A. (2001), Op. Cit. 35-43.

${ }^{79}$ DE WAAL, F. (2007), Op. Cit. 99-103.

${ }^{80}$ DIAMOND, J. (2007), Op. Cit. 39.

${ }^{81}$ DIAMOND, J. (2007), Op. Cit. 90-97. 
furtiva con fines recreativos o lucrativos, que ha llevado a muchas especies a su extinción, eliminando formas de vida, de comunicación y de convivencia social únicas en el Planeta.

Para definir la forma de lograr tales fines, reafirmamos los planteamientos de Pocar, quien sostiene que se considere titular de derechos a todo ser sensible, manifestando lo anterior en las regulaciones sociales y jurídicas ${ }^{82}$. De esta manera, incluso no sería tan ridículo como se piensa el que se puedan reconocer a los animales ciertos derechos "políticos", por ejemplo los que salvaguardan los modelos de relaciones con seres de su especie, conforme a sus particularidades etológica, dentro de una manada animal organizada jerárquicamente ${ }^{83}$.

Agrega además que si los animales tienen intereses análogos a los humanos, se les debe reconocer el derecho a tutelarlos con las mismas limitaciones que tienen los humanos, incluso reconociéndoles intereses que los humanos no tienen y el resto de los animales $\mathrm{si}^{84}$.

Claramente estaríamos frente a regulaciones de carácter socio-jurídicas que considerarían al animal no humano como un sujeto de derechos, demostrando un componente sociológico-cultural de relevancia, al resguardar efectivamente los derechos de criaturas no humanas capaces de asociarse, llegar a acuerdos y mantener lazos comunicativos-afectivos únicos en la naturaleza, preservables y valorables.

La importancia de esta propuesta precisamente radica en la necesidad de proteger y preservar un importante antecedente que explica nuestra propia evolución como animal, siendo más significativas y diversas las similitudes entre las especies sencientes que las diferencias en torno a la racionalidad e intelectualidad.

Las semejanzas, en efecto, desde el plano colectivo, no nos pueden dejar indiferentes, sobre todo luego de encontrar importantes elementos culturales, emocionales e incluso morales comunes en muchos animales no humanos, que, a su vez, nos llevan a la comprensión de comportamientos sociales esenciales de la humanidad, manifestadas a través del derecho y la organización histórica de las sociedades. En base a las conclusiones arribadas por muchos de los científicos y pensadores recientes aquí estudiados, es posible que deriven de nuestra propia animalidad.

\section{Bibliografía.}

- 24 HORAS. Proyecto busca que animales sean declarados "seres vivientes y sintientes" en Chile, en 24 Horas: https://www.24horas.cl/nacional/proyecto-busca-que-animales-sean-declarados-seresvivientes-y-sintientes-en-chile-4560426 [Última consulta: 20 de diciembre de 2020]

- BOEGE, K., y DEL VAL, E. Bichos vemos relaciones no sabemos: diversidad e importancia de las interacciones bióticas, en Revista Ciencias UNAM, Ciudad de México. (2011) 6. URL: https://www.revistacienciasunam.com/es/110-revistas/revista-ciencias-102/946-bichos.html

- CORDERO, M. y MARTÍNEZ, A. El parasitismo y otras asociaciones biológicas. Parásitos y hospedadores, en Parasitología Veterinaria, Madrid (1999).

- CNN. Los bonobos hablan como los bebés humanos, según estudios, en https://cnnespanol.cnn.com/2015/08/04/segun-estudio-los-bonobos-hablan-de-la-misma-formaque-lo-hacen-nuestros-bebes/ [Última consulta: 15 de diciembre de 2020]

- DE WAAL , F., Primates y Filósofos. La Evolución de la moral del simio al hombre (Barcelona, 2006).

- DIAMOND, J. El Tercer Chimpancé. Origen y futuro del animal humano (Barcelona, 2007).

- FISCHER, A. Los Canguros intentan comunicarse con los humanos para pedir ayuda, revela un estudio, en National Geographic en español: https://www.ngenespanol.com/animales/los-cangurospueden-comunicarse-con-humanos-revela-un-estudio/ [Última consulta: 18 de diciembre de 2020]

- FISCHER, A. Un robot espía se cuela a una manada de gorilas y descubre que cantan mientras cenan, en National Geographic en español: https://www.ngenespanol.com/animales/robot-capta-agorilas-cantando-a-la-hora-de-la-cena/ [Última consulta: 18 de diciembre de 2020]

- GOODALL, J., 60 Años en Gombe (Almeria, 2019).

- HERNÁNDEZ, J. Los murciélagos "conversan" sobre sexo, sueño y comida. en El País: https://elpais.com/ciencia/2020-12-08/los-murcielagos-conversan-sobre-sexo-sueno-ycomida.html [Última consulta: 14 de diciembre de 2020]

\footnotetext{
${ }^{82}$ LORA, L. (2015), Op. Cit. 3.

${ }^{83}$ POCAR, V., Los Animales No Humanos, Por una Sociología de los Derechos. Traducido por Laura N. Lora (Buenos Aires, 2013) 45.

${ }^{84}$ POCAR, V. (2013), Op. Cit. 45.
} 
- HERREROS, P. Descubren nuevo ritual funerario en chimpancés, en El Mundo: https://www.elmundo.es/blogs/elmundo/yomono/2017/03/25/descubren-un-nuevo-ritual-funerarioen.html [Última consulta: 18 de diciembre de 2020]

- INFOBAE. Los gorilas que posaron con un guardabosques para una selfie como si fueren humanos y que se hicieron virales", en INFOBAE: https://www.infobae.com/america/mundo/2019/04/20/losgorilas-que-posaron-con-un-guardabosques-para-una-selfie-como-si-fueran-humanos-y-que-sehicieron-virales/ [Última consulta: 15 de diciembre de 2020]

- LORA, L. De los sujetos no humanos como sujetos de derecho hacia los animales no humanos como titulares de derechos, en Instituto de Investigaciones Jurídicas y Sociales Ambrosio L. Gioja, Facultad de Derecho, Universidad de Buenos Aires, (2018). 8. URL: http://www.derecho.uba.ar/investigacion/investigadores/publicaciones/2018-lora-de-los-sujetosno-humanos-hacia-los-animales-no-humanos.pdf

- LORA, L., Problemas actuales en la consideración socio-jurídica de los animales no humanos como sujetos de derecho, en Nuevos debates en filosofía y ciencia política (Mar del Plata, 2015) 9. URL: http://www.derecho.uba.ar/investigacion/investigadores/publicaciones/lora-problemas-actuales-enla-consideracion-socio-juridica.pdf

- MEDIAVILLA, D. Primer caso de comunicación entre humanos y animales salvajes, en El País: https://elpais.com/elpais/2016/07/21/ciencia/1469112502_711822.html [Última consulta: 11 de diciembre de 2020]

- MISSE, J. Los pactos más extraños del mundo animal, en La Vanguardia: https://www.lavanguardia.com/natural/20160321/40592697210/simbiosis-pactos-animales.html [Última consulta:16 de diciembre de 2020]

- NATIONAL GEOGRAPHIC. Beluga juega rugby con un marinero en medio del océano", en National Geographic en español: https://www.ngenespanol.com/animales/beluga-juega-rugbymarinero-oceano/ [Última consulta: 15 de diciembre de 2020]

- NATIONAL GEOGRAPHIC, Los perros reconocen palabras aunque las digan desconocidos, en National Geographic en Español: https:/www.ngenespanol.com/animales/perros-reconocenpalabras-aunque-digan-desconocidos/ [Última consulta: 18 de diciembre de 2020]

- NOTICIAS DE LA CIENCIA Y LA TECNOLOGÍA. Diferencia cultural entre dos comunidades vecinas de bonobos, en https://noticiasdelaciencia.com/art/39400/diferencia-cultural-entre-doscomunidades-vecinas-de-bonobos, [Última consulta: 15 de diciembre de 2020]

- POCAR, V., Los Animales No Humanos, Por una Sociología de los Derechos. Traducido por Laura N. Lora (Buenos Aires, 2013).

- POZAS, P. La UNESCO debe declarar a los grandes simios "Patrimonio Vivo de la Humanidad", en El Diario: https://www.eldiario.es/caballodenietzsche/grandes-simios-patrimonios-vivoshumanidad_132_2278518.html\#: :text=S\%C3\%ADguelo\%20en\%20redes-

,La\%20Unesco\%20debe\%20declarar\%20a\%20los\%20grandes,Patrimonio\%20Vivo\%20de\%20la $\% 20$ Humanidad'\&text=Los\%20grandes $\% 20$ simios\%20 (bonobos\%2C\%20orangutanes,siendo\%20 diezmadas\%20por\%20numerosas\%20causas. [Última consulta: 20 de diciembre de 2020]

- RABINOVICH-BERKMAN, R., Cetera Animalia. A partir del fallo Sandra, en La Ley, doctrina judicial (2015) 5 .

- RABINOVICH-BERKMAN, R. ¿Contratos con otras especies?, en Pensar en Derecho, Año 5, №12 (2018), 102-107. URL: http://www.derecho.uba.ar/publicaciones/pensar-enderecho/revistas/12/contratos-con-otras-especies.pdf

- RABINOVICH-BERKMAN, R., Nuevas reflexiones sobre el concepto de persona, en Inmanencia: Revista del Hospital Interzonal General de Agudos Eva Perón, Vol. 2, No 1 (2012). 5-7.

- RABINOVICH-BERKMAN, R., Sobre las sociedades con otras especies, en Nuevos debates en filosofía y ciencia política, (2015) 8.

- ROMERO, J., Jane Goodall: Una visión crítica, en La Mujer en la Historia de la Ciencia (2006), 7276. https://repositorioinstitucional.ceu.es/bitstream/10637/6339/1/Mujer_BorregoGutierrez_MJ_2008. pdf\#page $=71$

- RTVE. Chimpancés y bonobos pueden entenderse con gestos, en https://www.rtve.es/noticias/20180228/chimpances-bonobos-pueden-entendersegestos/1686264.shtml [disponible el 16 de diciembre de 2020] 
- RUIZ, M. Humano y chimpancé comparten el $99 \%$ del ADN, en El País: https://elpais.com/diario/2005/09/01/sociedad/1125525601_850215.html, [Última consulta: 10 de diciembre de 2020]

- SALAS, J. Los tres "funerales" que demuestran la tristeza de los gorilas, en el País: https://elpais.com/elpais/2019/04/04/ciencia/1554378154_099642.html [Última consulta: 12 de diciembre de 2020]

- SINGER, P., Liberación Animal (Barcelona, 2018).

- WESTHOFF, R. Amigos inesperados: 6 increíbles relaciones simbióticas en la naturaleza”, en El Definido: https://eldefinido.cl/actualidad/mundo/7618/Amigos-inesperados-6-increiblesrelaciones-simbioticas-en-la-naturaleza/ [Última consulta: 20 de diciembre de 2020]

- ZÁRATE, C. Un Nuevo Estatus Jurídico para los Animales No Humanos (Santiago de Chile, 2020) 28 y 29.

- ZAFFARONI, E., La Pachamama y el Humano (Buenos Aires, 2017). 